\title{
Mining the British Isles oak tree-ring data set. Part A: rationale, data, software, and proof of concept.
}

\author{
Anthony M. Fowler ${ }^{1}$, Martin C. Bridge ${ }^{2,3}$ \\ 1. School of Environment, The University of Auckland, Auckland, New Zealand. \\ 2. University College London, Institute of Archaeology, London, UK. \\ 3. Oxford Dendrochronology Laboratory, Oxford, UK.
}

\section{Abstract}

From stuttering early beginnings, archaeological oak dendrochronology in the British Isles developed rapidly in the latter decades of the $20^{\text {th }}$ century, to the present situation where dozens of new crossdated site chronologies are produced each year. Although unevenly spread in both space and time, the available data set is now so large (several thousand sites) that it has the potential to be mined for applications that were not envisaged when the data were originally collected. Here we compile available data into an oak database of archaeological and modern (living) sites, develop a software tool to visualise spatial patterns and correlations, and explore six potential data-mining applications (crossdating methodology, crossdating error detection, regional chronologies, pointer years, provenancing, past climate reconstruction). Results indicate variable data-mining potential, but with viable prospects in each case.

\section{Introduction}

Although the potential of dendrochronology for applications in British archaeology was implicitly recognised in the early $19^{\text {th }}$ century (Babbage, 1837), it was another 100 years before substantive application began. AWG Lowther measured sequences of rings in Roman timbers in the 1930s and John Harvey measured sequences from a number of chests in Westminster Abbey, using a graticule, as early as 1949. Harvey handed his measurements to Lowther who tried internally crossmatching the sequences statistically, and also to date them by comparisons with known weather records, major trends in ring width, outstanding wide and narrow 'pointer years', and correlations with varve sequences (Lowther 1951). Later in the 1950s, Schove and Lowther (1957) tried dating building timbers and a boat wreck, relying on similar comparison techniques. Although much of this early work has subsequently been shown to be incorrect (Miles and Bridge, 2008), it appears that Lowther did correctly date a stile from the Deep Chest in the Muniment Room (Westminster Abbey). Interestingly, the fact that the chest was subsequently shown to probably have been made from German timber (Miles and Bridge, 2008) may indicate undocumented early cooperation with the German researcher Huber - dating against his material, without realising the origin of the timber.

Compared to contemporary developments in North America and in Germany, the early British developments identified above were limited in scope and success - and Baillie (1982, p. 93) was probably not far from the truth when he claimed that "....in the late 1960s no one in the British Isles had a clue about the practicalities of [tree-ring] chronology building [and] the prevailing attitude amongst archaeologists and palaeobotanists was one of sheer scepticism". Moreover, in the early 1970s German tree-ring researchers expressed the view that, because of the maritime climate of Britain, dendrochronology would "... require a massive onslaught from many different regional centres of study" (Berger et al. 1971, p. 5). 
Fortunately, the views expressed by Berger et al. (1971) proved to be overly pessimistic. By the early 1970s the dendrochronological potential of Irish oak had been emphatically demonstrated by Baillie and colleagues at Queen's University, Belfast. This work was based on sound dendrochronological principles, starting with crossmatching sequences from living or recently felled trees to establish a firmly dated sequence, and overlapping older and older sequences - building absolutely dated chronologies, which eventually enabled 'floating' chronologies developed from material collected earlier to be themselves absolutely dated. Also in the 1970s, John Fletcher was establishing chronologies for English oak, although much of his work centred on art-historical material which later proved to have continental European origins, leading to some confusion in his ideas about different types of oak growing in Britain (Baillie et al. 1985).

Initially, much of the historical English oak material had to be dated against Continental or Irish chronologies, but eventually the replication of English material and the firm anchoring to chronologies of living oaks made dating of new material almost routine. An enormous input to the building of English dendrochronology was provided by the government agency English Heritage (and its predecessor organisations) which maintained a laboratory at Sheffield University and helped in the training of new people coming into the field. By the turn of the century, dozens of new chronologies were being produced each year, and by early 2015 the total count was of the order of 3000 chronologies, predominantly from southern and central England but with significant contributions from much of the rest of the British Isles. We contend that the size of the available data set and its large (though uneven) geographical spread provides an opportunity to review current practice and address additional research questions unrelated to the primary dating purpose. Possible applications are listed below.

\section{Review of current practice.}

a. Crossdating methodology. British dendrochronology developed in a data-sparse context and evolved with theory and practice (what worked). The fundamentals of the methodology developed by Baillie in Ireland persist, but there is considerable divergence with respect to the details. This is an opportune time to critique current practice as many of the original practitioners approach retirement. We argue that the current database could usefully be mined to empirically review persisting questions such as: the relative merits of different types of high-pass filtering (designed to maximise the common signal); the probability of obtaining threshold statistical matches by chance; and the practical minimum sample length that can be crossdated.

b. Crossdating error detection. Tree-ring dating errors occur and it is reasonable to assume that some of the several thousand assigned dates may be incorrect. Inter-comparison of thousands of sites permits a systematic automated review of all dates. We expect that this would identify potential crossdating issues, where follow up is warranted.

c. Regional chronologies. As the available data set has expanded, British dendrochronologists have increasingly utilised regional composite chronologies for dating purposes, although there is still an emphasis on matching against individual sites. Regional chronologies are useful, because combining sites tends to enhance the common signal, and because making fewer comparisons avoids statistical significance issues (multiplicity) when comparisons are made against many individual 
sites. However, it is unclear whether the stronger signal in regional chronologies is simply a consequence of increased sample depth or if in fact there are real regional-scale differences. Mining an oak database with a wide spatial distribution should facilitate detailed assessment of the value of regional chronologies.

\section{Additional research questions.}

The potential to explore regional patterns was a key motivator behind the current study. Despite some notable gaps, we judge there to be sufficient spatial coverage over the $2^{\text {nd }}$ millennium CE to realistically explore evolving spatial patterns over much of the British Isles. In this context we see three interrelated applications (which in turn overlap with "c", above).

d. Pointer years. Although oak dendrochronology in the British Isles is dominated by correlation analysis, the use of pointer years has a long tradition and recent work has identified pan-European oak pointer years (Kelly et al., 2002). Analysis of a composite database will show if there are distinct regional patterns. We would expect to see a mixture of pan-European, pan-British, and regional pointer years, and to resolve the relative importance of these.

e. Provenancing. A number of attempts have been made to provenance British Isles oak timbers, with mixed success. Computer-assisted mining of the oak database should allow fast implementation of existing methods and facilitate additional levels of analysis. An example of the latter is determining if there is a minimum regional site density for provenancing analysis to be viable.

f. Past climate. Implicit in several of the comments made above is the presumption that regional patterns exist and an assumption that they may well evolve through time. If both are correct, and because it is axiomatic that inter-annual climate variability is the cause, then identification of evolving spatial patterns over the $2^{\text {nd }}$ millennium CE should be indicative of associated changes in climate forcing. If spatial patterns can be ascribed to known regional climate drivers, then millennial-scale climate reconstruction may be feasible.

The bullet points above identify six ways that a comprehensive British Isles oak tree-ring database could be mined to provide information beyond the typical dating underpinning the building of each site chronology. The research presented here is a preliminary 'proof-of-concept'. To this end, we have assembled a database of nearly 2000 sites and have developed a software tool (Oak Mapper) to visualise and analyse it. The data and Oak Mapper are detailed in the following two sections. Following this we present preliminary analyses pertaining to each of the six potential applications. The intention is to identify those with potential worth pursuing - with more detailed analysis of those showing promise to follow. 


\section{Data}

The oak database is constantly increasing, but, for the purposes of this paper, consists of 1853 mean ring width site chronologies, supplemented by living-tree sites available as mean ring width (54) or as indexed series (14). Sources are in the Acknowledgements. The database includes 68 chronologies from living oaks. These sites have a mean chronology length of 215 years, with a range of 100-556 years, and dominate the database from about 1800 . The over 2000 available archaeological site chronologies have sample depths ranging from one to more than 30 timbers. This potential data set was reduced by excluded all inner-London sites and chronologies - because London has a long history of importing timber from a wide hinterland, making site location unhelpful in the mapping context of this research. We further reduced the data set by excluding sites with fewer than three timbers, although it should be noted that many of the 1853 retained archaeological chronologies will have component parts with reduced sample depth, primarily at the beginning and/or end of the series. The database is dominated by sites containing 5-10 series.

Sample depth of the oak database for the $2^{\text {nd }}$ millennium CE (Fig. 1) rises gradually from 65 sites at $1000 \mathrm{CE}$ to over 450 sites in the mid $14^{\text {th }}$ century, increases more rapidly to a mid $15^{\text {th }}$ century peak of 855 sites, then declines with two distinct steps centred on about 1700 (155 sites) and 1900 (70). This temporal distribution largely reflects the surviving structures for the first part of the time period, and the buildings of interest in the middle part of the range. Buildings after ca. 1600 tend to either have records relating to the date of building, or can be stylistically dated to within a short period, and are therefore less often the subject of dendrochronological enquiry.

The geographical spread of the data (Fig. 2) is quite extensive, but with notable biases. Some counties or other regions have in the past run dating projects (Shropshire, Somerset, Hampshire and Oxfordshire, and North West Wales) whilst the Royal Commission on Historic Monuments in England (RCHME) ran a project in Kent. Some areas have mostly stone buildings. Although these generally contain wooden roofs and floors, they tend to be less well represented (e.g. Northamptonshire, Cumbria). In addition, some areas are underrepresented because they have proved more difficult for dating - the south west peninsular for example, although English Heritage have funded projects in Devon to try and overcome these difficulties. South Wales is another poorly represented area, probably partly related to non-survival of historic fabric.

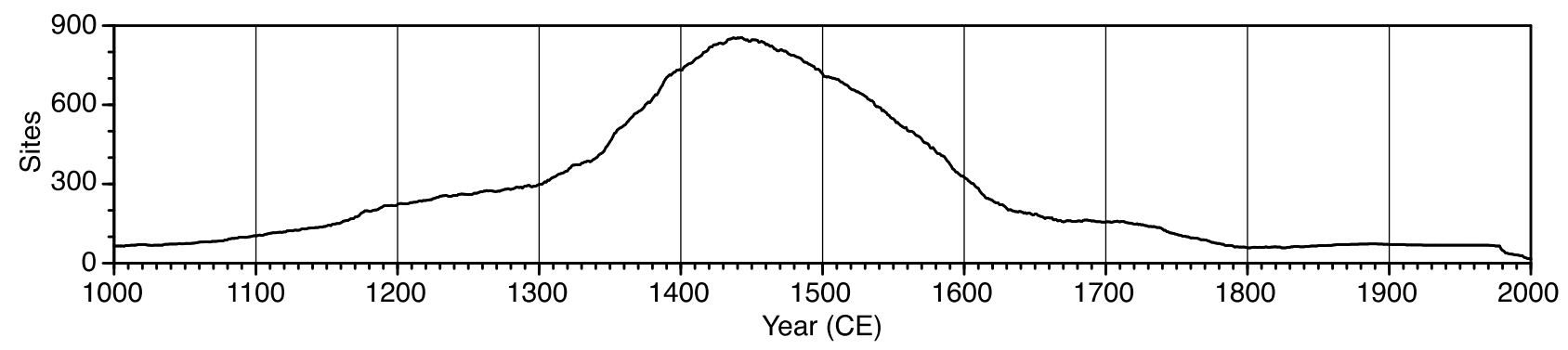

Fig. 1. Oak database sample depth. 


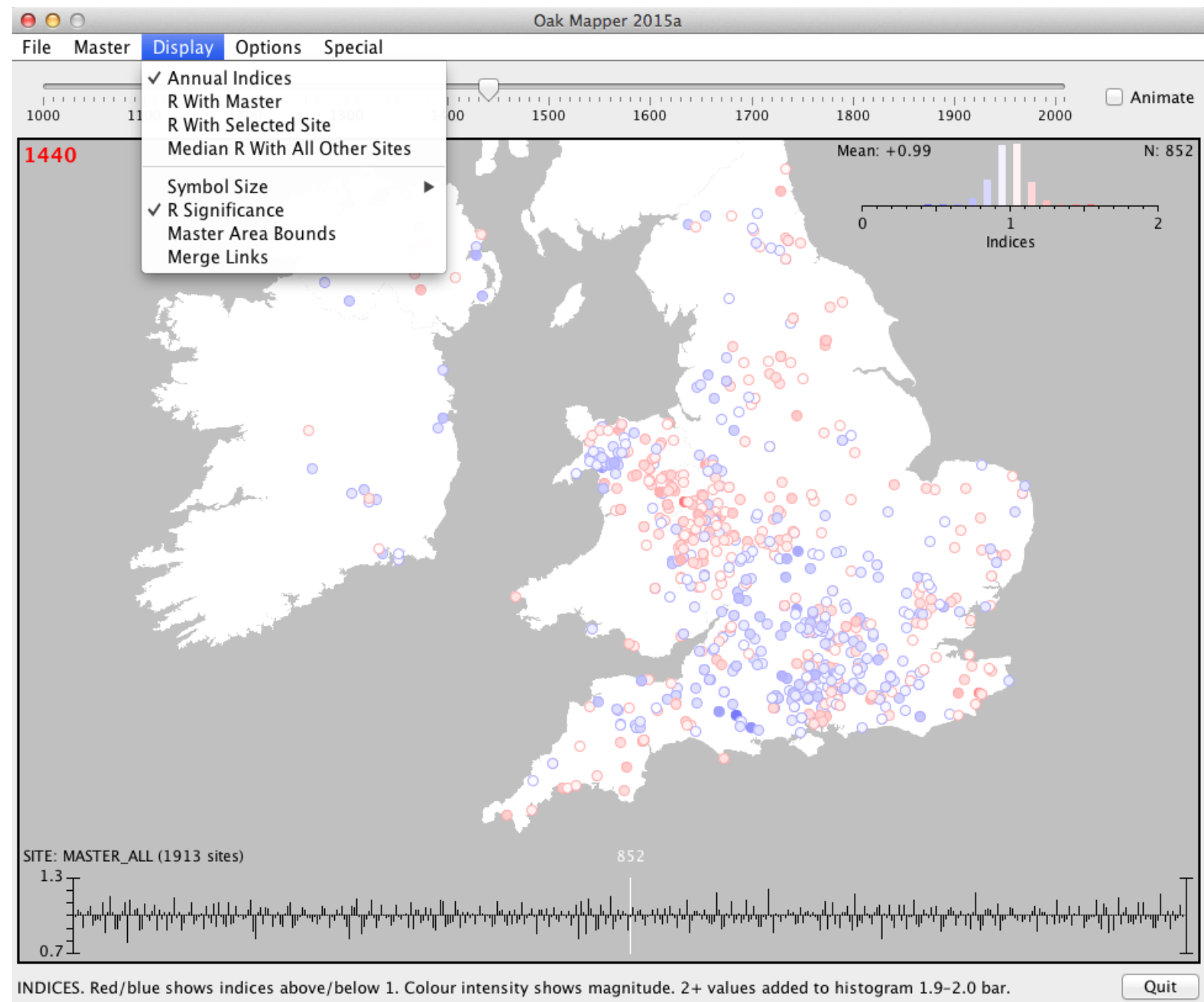

Fig. 2. Oak Mapper graphical user interface, showing the spatial distribution of sites with data at $1440 \mathrm{CE}$ (many sites partially or completely obscured). The histogram in the top-right corner shows the distribution of indices, calculated using an 8-year spline (see "Methods"). Histogram colours correspond to the mapped circles: blue/red indicates narrow/wide rings respectively, with increasing colour intensity indicating larger deviations from one. The time series of indices across the bottom is part of a robust mean (Mosteller and Tukey, 1977) master chronology constructed from all available sites. The vertical white line in the middle of this series is the current year mapped (1440 here), with the number of sites comprising the master in the plotted year ( 854 here) above it. Total sites comprising the master (1913 here) is shown in brackets in the series label. The current year is selected using the scroll bar above the map, or the display can function as a year-by-year slide show by checking the "Animate" checkbox. Other program functions and display options are accessed through drop-down menus (see text for details, and other figures for examples) and the text below the plotted time series provides a terse description of what is displayed. 


\section{Methods}

\section{Data pre-processing.}

The oak database is predominantly mean ring-width chronologies, mostly in the format of $1 / 100^{\text {th }} \mathrm{mm}$ although other units are used in some, and 14 sites are in the form of indexed series. To minimise inconsistencies, all series were transformed into indices by fitting a smoothing spline to the original data (indices or raw ring widths) and dividing each annual data value by the fitted curve. For indexed living-tree chronologies this process involves double standardisation. For consistency with current practice, the default fitted curve is a very flexible smoothing spline with $50 \%$ frequency response at eight years (Fig. 3), but alternatives are also explored.

Double standardisation provides the flexibility to include sites that are only available in indexed form. Because the second standardisation (applied by us) uses a highly flexible smoothing spline (Fig. 3) we will normally remove additional decadal-scale variance. The more conservative the standardisation used by the original researchers (e.g. using stiff splines or straight lines), the closer the result will be to standardising against mean ring widths. In cases where the first standardisation is comparable to the flexibility used by us, the second step has little impact because the associated decadal-scale variability has already been removed.

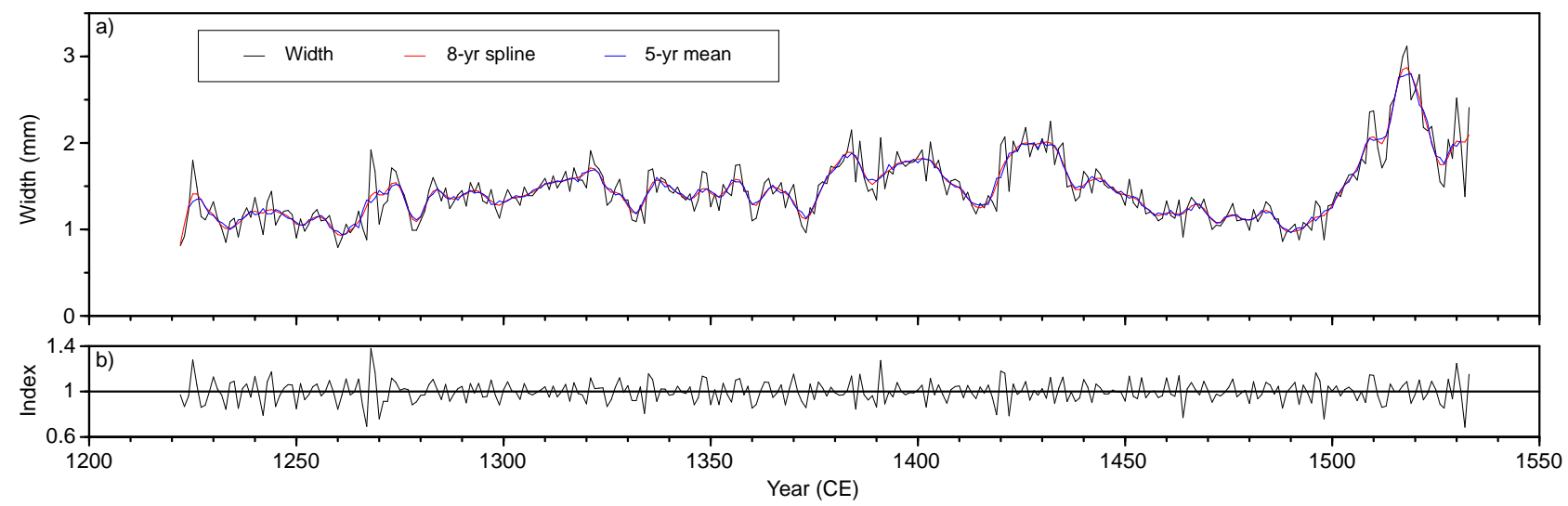

Fig. 3. Example of default pre-processing standardisation. a) Raw ring widths for a site in western Wales (St David 3). Fitted smooth curves are an 8-year spline (red) and a 5-yr running mean (blue). b) Indices derived by dividing the ring width by the corresponding value of the 8-year spline. The flexibility of the fitted spline is adjustable within Oak Mapper. The 8-year spline is the closest match to the still widely-used CROS program which removes the 5-year running mean (Baillie and Pilcher, 1973). 


\section{Analysis (Oak Mapper).}

Visualization (especially mapping) and correlation analysis are two core elements of the methodology, both implemented through Oak Mapper, a bespoke GUI-driven Java software application. On start up the program reads the oak database, applies the default pre-processing detailed in the previous section, and maps the resulting indices. An indices histogram is also plotted, along with a robust mean (Mosteller and Tukey, 1977) master chronology. Fig. 2 shows all of these elements.

Simple nearest-neighbour merging of sites can be applied, up to a user-specified distance limit of 0-100 km. The location of the merged site is determined by averaging the latitudes and longitudes of the constituent sites but, to handle possible outliers, the merged chronologies are built using a robust mean. Note that a zero-distance merging combines sites with identical locations (e.g. multiple phases of the same building). For example, zero-distance merging reduces the number of sites at 1440 (Fig. 2) from 854 to 745 . Merged sites may be discontinuous series.

Oak Mapper has three correlation analysis and display options: site correlations with the current master; correlations with a selected site, and; median correlation of each site with every other site. Correlations are Pearson's product moment correlation coefficients for a user-specified window (default 51 years) centred on the current year, with values calculated and plotted only if there is complete overlap within the window. Correlation strength is displayed by colour intensity and the site symbol size can optionally be scaled proportional to Student's t statistic (sensu Baillie and Pilcher (1973)) to emphasise differences and visually indicate statistical significance.

Fig. 4 shows the results of combining several of the options noted above. In this case the master chronology is for a southern England subset (box), $30 \mathrm{~km}$ merging has been applied, and correlations of each site with the master are mapped. Merging has "reduced" our original 854 sites to 107 merged sites, 83 of which have complete data for the 51-year window centred on 1440 and are therefore mapped in Fig. 4. A few sites are unchanged, because they are at least $30 \mathrm{~km}$ away from their nearest neighbour, most are composites of up to 10 original sites, but several merged sites over central and southern England have over 100 sites.

Oak Mapper is an interactive program, controlled through its graphical user interface. The data are read at start up and cannot be changed, but the user has full on-the-fly control on what is mapped. This includes the flexibility of the standardisation spline, whether ring widths or correlations are mapped, the width of the correlation window, and merging distance. Alternative master chronologies can be chosen, via the "Master" menu, and individual sites (raw or merged) can be selected by clicking on them, which displays their time series. The display can be animated to show a year-by-year sequence, the displayed map can be exported as a PNG file and data can be exported as a CSV file (current site, master chronology, all sites for the selected year). The "Special" menu accesses analytics, such as pointer year analysis (Fig. 8, below). 


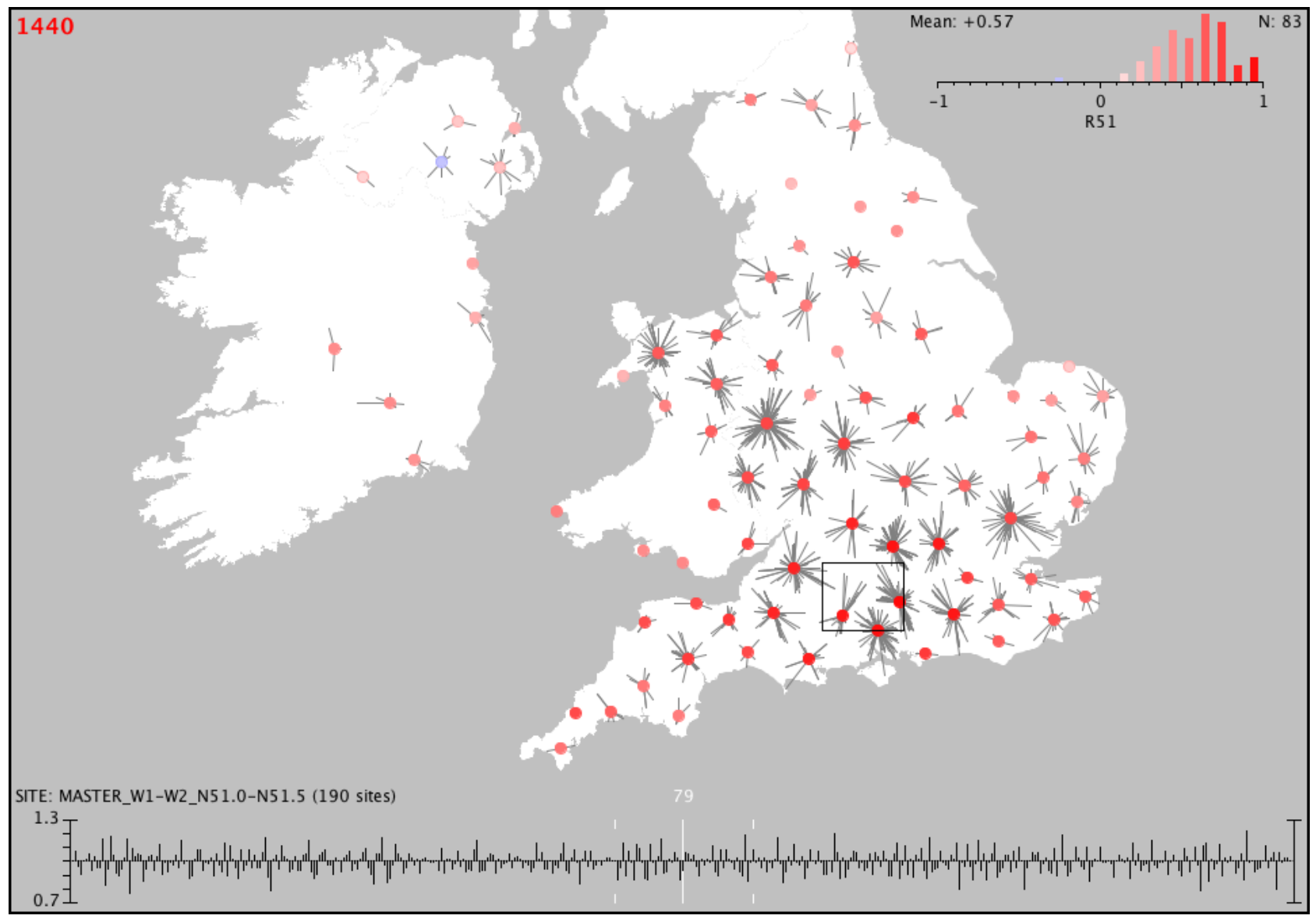

Fig. 4. Example Oak Mapper correlation analysis. The master chronology is built using the 190 sites within the displayed southern England box (bounds: $1 \mathrm{~W}, 2 \mathrm{~W}, 51 \mathrm{~N}, 51.5 \mathrm{~N}$ ). Nearest-neighbour merging gives 79 sites with complete data over the 51-year correlation window, denoted by vertical white dashes either side of the master central year marker. Lines radiating out from site symbols show locations of sites contributing to each merged site (many lines are obscured by others or by the merged-site symbols). Symbol colours represent the correlation of each merged site with the master and the histogram is adjusted accordingly.

\section{Crossdating methodology}

Modern British dendrochronology has its methodological origins in the work of Mike Baillie's research group at Queen's University, Belfast. The fundamentals of Baillie's methodology (high-pass filtering; minimum series length; sliding series against each other; correlation-based goodness-of-fit statistic, and; statistical significance testing - commonly Student's t) were well established by the 1970s and persist to the present day. There have been some local developments, such as alternative statistical methods developed by the Nottingham lab (Litton and Zainodin, 1991), and there are areas of disagreement amongst practitioners (e.g. varying opinions on the minimum series length that should be considered eligible for crossdating). Also, the purely statistical method used at Nottingham can be criticised for not employing a visual plot checking stage, potentially resulting in errors going undetected, especially near the beginning or end of a sequence, despite an acceptable statistical match. There has, however, been no major review of the method since it was first developed in the British Isles by Baillie and co-workers. This probably reflects the efficacy of the methodology (it worked). It is our contention that the available data base is now large enough to review the core crossdating methodology - which we demonstrate by exploring alternative high-pass filtering options. 
High-pass filtering of British Isles oak chronologies has been common practice since the original CROS program of Baillie and Pilcher (1973) was developed and the source code made freely available. Because much of the decadal-scale variation in oak ring widths is tree and site specific, removing it maximises the common signal across sites, resulting in stronger inter-site correlations. Baillie and Pilcher (1973) achieved this by fitting a 5-year running mean to the data and deriving yearly indices as percentages of the local moving average - a method essentially analogous to the common standardisation method (implemented in Oak Mapper) of dividing ring width by the local value of the fitted curve. A spline with $50 \%$ frequency response at eight years ("Spline 08") is similar to a 5-year mean, in terms of fit to the data (Fig. 3), and was therefore adopted as a suitable default option in Oak Mapper.

Table 1 shows the impact on inter-site and site-master correlations of varying the flexibility of the fitted standardisation curve (columns). The results support the contention that high-pass filtering of oak using a highly flexible curve is effective at enhancing the common signal - indeed the overall highest correlations were obtained with a fitted curve even more flexible than a 5-year moving average. There are exceptions when correlations are relatively low, but differences are minor across the range of splines investigated here. Tabled correlations are multi-site means (each mean represents a frequency distribution of correlations, each with its own significance level), so only indicative values for statistical significance can be determined. With that caveat in mind, the results in Table 1 indicate highly significant correlations $(p<0.001)$ between sites and the master chronology, for all spline fits and across all centuries. Statistical significance is much lower for inter-site correlations (typically $\mathrm{p}<0.05$ ).

Table 1. Impact of standardisation curve flexibility on inter-site and site-master correlations. Spline 06 through Spline 16 are standardisation curves of decreasing flexibility, the number denoting the $50 \%$ frequency response at $6,8,10,12,14$, and 16 years (an example Spline 08 curve fit is shown in Fig. 3). Correlations are for a 51-year window centred on the last year of each century (rows). The first of each tabled pair is the across-site mean of median inter-site correlations. For example, each of the 529 sites with data for the full 51-year window centred on 1500 is correlated with every other available site, the median for each site is calculated (from 528 correlations), then the 529 medians are averaged. The second correlation is the average of site correlations with a master chronology calculated from all available sites. Shading highlights the highest combined correlations for each century and the last row shows means for the tabled values (i.e. overall performance for each spline).

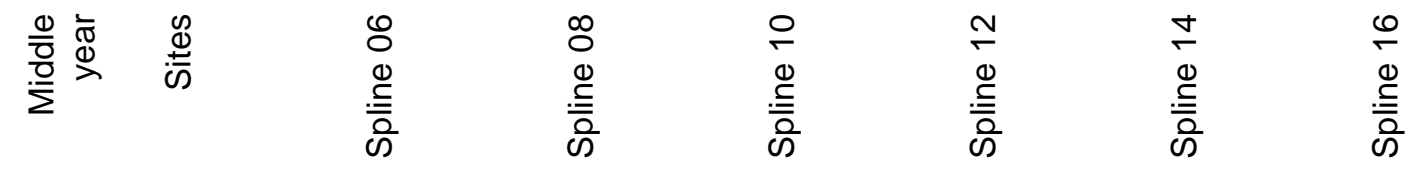

\begin{tabular}{rr|lllllll|}
1900 & 66 & $0.30 \mid 0.56$ & $0.29 \mid 0.55$ & $0.27 \mid 0.53$ & $0.26 \mid 0.52$ & $0.25 \mid 0.51$ & $0.24 \mid 0.51$ \\
1800 & 31 & $0.25 \mid 0.50$ & $0.27 \mid 0.52$ & $0.28 \mid 0.52$ & $0.28 \mid 0.52$ & $0.28 \mid 0.52$ & $0.27 \mid 0.52$ \\
1700 & 96 & $0.47 \mid 0.67$ & $0.45 \mid 0.66$ & $0.42 \mid 0.64$ & $0.40 \mid 0.62$ & $0.38 \mid 0.61$ & $0.37 \mid 0.60$ \\
1600 & 169 & $0.29 \mid 0.53$ & $0.29 \mid 0.53$ & $0.29 \mid 0.54$ & $0.29 \mid 0.54$ & $0.29 \mid 0.54$ & $0.29 \mid 0.53$ \\
1500 & 529 & $0.36 \mid 0.59$ & $0.35 \mid 0.59$ & $0.35 \mid 0.59$ & $0.35 \mid 0.58$ & $0.34 \mid 0.57$ & $0.33 \mid 0.57$ \\
1400 & 469 & $0.30 \mid 0.54$ & $0.28 \mid 0.52$ & $0.27 \mid 0.51$ & $0.27 \mid 0.51$ & $0.27 \mid 0.51$ & $0.27 \mid 0.51$ \\
1300 & 178 & $0.26 \mid 0.50$ & $0.28 \mid 0.52$ & $0.29 \mid 0.53$ & $0.30 \mid 0.53$ & $0.30 \mid 0.53$ & $0.30 \mid 0.53$ \\
1200 & 157 & $0.42 \mid 0.63$ & $0.39 \mid 0.61$ & $0.37 \mid 0.60$ & $0.35 \mid 0.58$ & $0.34 \mid 0.57$ & $0.32 \mid 0.56$ \\
1100 & 75 & $0.27 \mid 0.52$ & $0.26 \mid 0.51$ & $0.26 \mid 0.52$ & $0.27 \mid 0.53$ & $0.27 \mid 0.53$ & $0.27 \mid 0.52$ \\
1000 & 52 & $0.31 \mid 0.57$ & $0.28 \mid 0.54$ & $0.26 \mid 0.53$ & $0.24 \mid 0.51$ & $0.24 \mid 0.50$ & $0.23 \mid 0.50$ \\
\cline { 4 - 8 } Means: & & $0.32 \mid 0.56$ & $0.31 \mid 0.56$ & $0.31 \mid 0.55$ & $0.30 \mid 0.54$ & $0.30 \mid 0.54$ & $0.29 \mid 0.54$
\end{tabular}




\section{Crossdating error detection}

Fig. 4 shows a clear pattern of decreasing correlations (lighter red dots) moving away from the southern England sites used to build the master chronology. Although correlations are weakest for northern and western sites, a notable Northern Ireland outlier is evident where the correlation is actually negative (blue dot). Unpicking the relevant data reveals that one site (Blackwater Mean) has very weak correlations against all other sites (Fig. 5a). Checking back with one of the original researchers revealed a two-year typographical error in the chronology start year recorded in the data file header line (Dave Brown, pers. com.) ${ }^{1}$. Fixing the header brings the chronology into line with the oak database (Fig. 5b).

a)

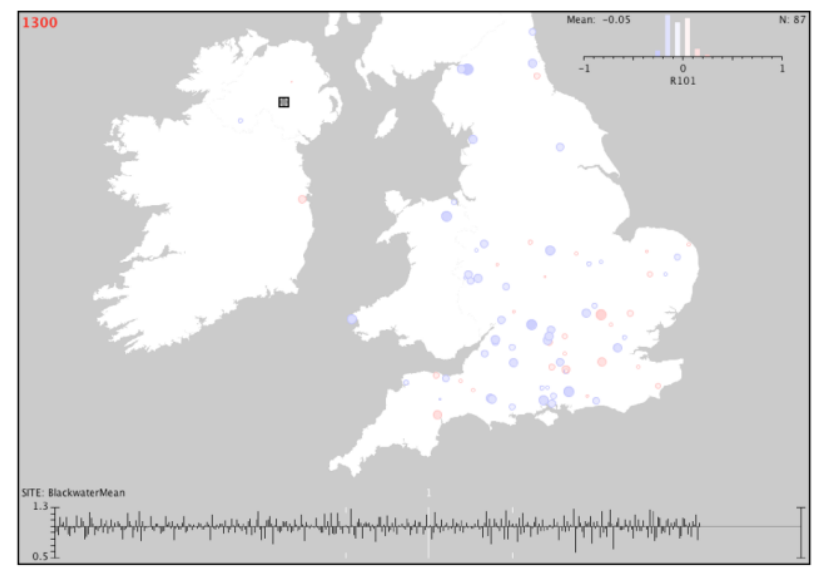

b)

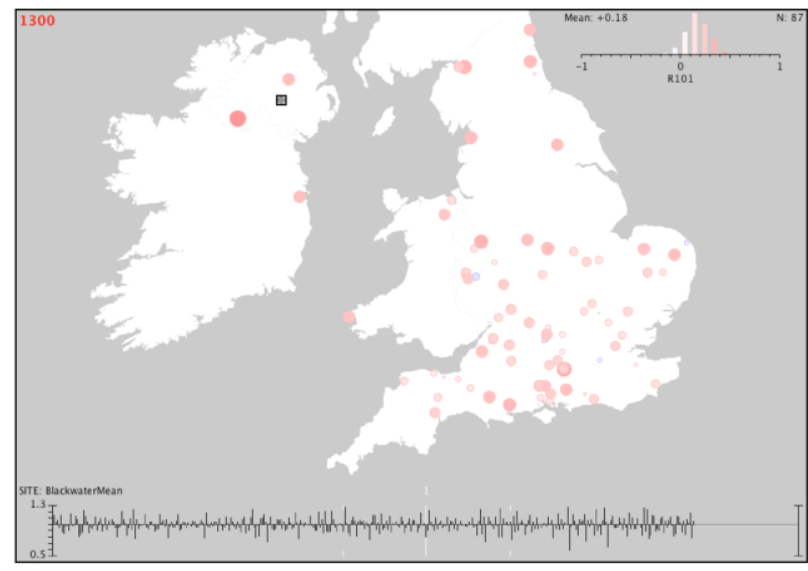

Fig. 5. Example of the identification of a database error. a) The selected site (Blackwater Mean, square symbol) is correlated against 87 sites (circles) with full data over the 101-year window centred on 1300 . Generally low correlations centred close to zero (mean -0.05) indicate no match between the selected site and the oak database. b) Corresponding plot after fixing the two-year error in the chronology start date. Larger and mostly red dots indicate convincing crossdating, especially against northern and western sites.

Although the Blackwater case is an example of a transcription error rather than a crossdating error, it usefully demonstrates the utility of the oak database for screening for potential errors. Note though that "potential" is an important caveat here, because low correlation is not itself evidence of crossdating error. Weak correlations may be a consequence of low sample depth, or they may be caused by the sort of distancerelated decay shown in Fig. 4 (including possible long-distance timber import in extreme cases). With this in mind, probably all that can reasonably be expected of the sort of mass correlation used here is the flagging of sites worth rechecking on a case-by-case basis. As shown here, mapping is a useful method for identifying and displaying potential errors, although an automated approach that lists 'suspect' sites would be a more efficient and objective method.

\footnotetext{
1 "Blackwater Mean" was constructed in May 2001 to replace the original "Blackwater Three" chronology constructed by Mike Baillie and noted in his 1982 book Tree-Ring Dating and Archaeology. The start date of the Blackwater Three chronology was $1010 \mathrm{AD}$, which was correct.
} 


\section{Regional chronologies}

A ubiquitous feature of Table 1 is the higher mean correlations of sites against the all-site master, compared to mean inter-site correlations. Although quite variable from century to century, the differences are consistently large, with variance explained $\left(R^{2}\right)$ typically increasing from about 9\% (inter-site) to 30\% (site with master). The impact on statistical significance is especially noteworthy - in the case of Spline08 standardisation, the mean correlation increase from 0.31 to 0.56 (Table 1) corresponds to a decrease in the probability of a chance match from ca. $1.34 \%$ to $<0.01 \%$. What we are seeing here is the classic enhancement of the common signal with increasing sample depth, even though using an all-site master ignores any potential regional signal.

The correlation distance-decay apparent in Fig. 4 is suggestive of a regional pattern, but is confounded by the fact that the sites relatively close to the southern England master box are within the region of highest site density. Because of the sample depth effect (above), it is possible that the apparent spatial pattern may be a merging artefact, rather than be indicative of real regional differences. However, a similar analysis, using Ireland sites to construct the master chronology (Fig. 6) clearly shows that this is not always the case. Here there is a distinctive pattern of declining correlations moving southeast across Wales and England and sample depth cannot be the explanation (cf. the merge links in Fig. 4 which are a sample depth guide). Interestingly though, the spatial pattern in Fig. 6 is not consistent with time. There are periods in the second millennium where correlations with Ireland are similar across Wales and England (and sometimes much stronger than shown in Fig. 6) whereas at other times there is essentially no relationship. Similar analyses for other regions (not shown) suggests that non-stationary relationships are characteristic, although in some cases (e.g. northern vs. southern England) the pattern persists but varies significantly in strength.

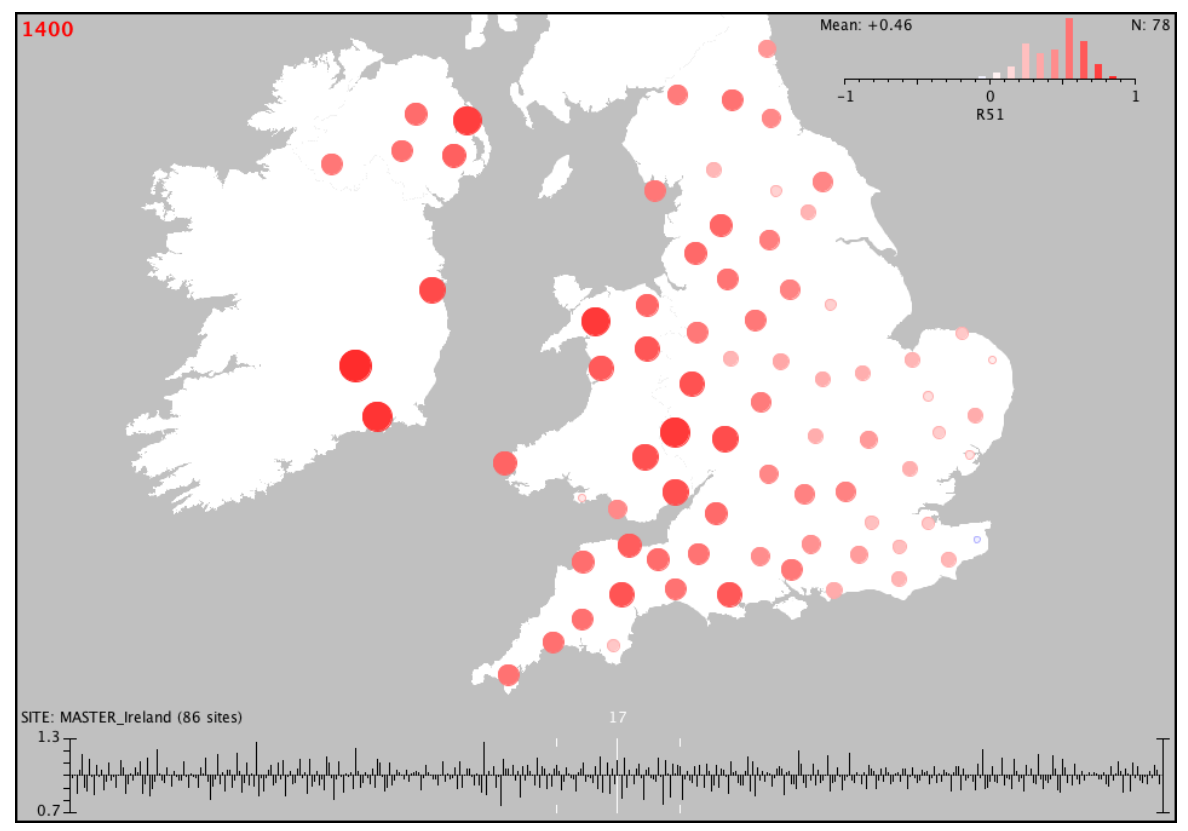

Fig. 6. Correlation of merged sites $(30 \mathrm{~km})$ with a master chronology built from 86 sites in Ireland. Colour intensity shows correlation strength (see histogram) and circle area (scaled to Student's t) is a guide to statistical significance. Correlations are for a 51-year window centred on 1400. 


\section{Pointer years}

Investigation of pointer years is most meaningful when there is good spatial coverage across the full area of interest. In this context, the oak database is reasonable through most of the second millennium, although site density drops off significantly in the last decade of the $20^{\text {th }}$ century. Some regions are persistently thinly represented (e.g. northern England, Fig. 7) and there are notable intermittent spatial gaps, including much of southern Ireland from the mid-1 $17^{\text {th }}$ century through the $18^{\text {th }}$ century and Wales until the $14^{\text {th }}$ century (Fig. $7 a$ ).

With the above spatial and temporal caveats in mind, yearly mapping of site indices reveals a plethora of spatial patterns. At either extreme are pan-British Isles pointer years where almost all sites have wide/narrow rings (Figs. 7a,b), often with no clear evidence of regional gradation. Exceptions are typically sites where the year in question is close to the beginning or end of the series, with associated low sample depth. 'Partial' pointer years are also common, where there is a dominant signal, but also a clearly demarcated regional exception. One such case is 1241, where narrow rings are common over most of the British Isles, but with a reversed pattern over East Anglia (Fig. 7c). This particular case repeats, but regional patterns are characterised by heterogeneity. Finally, some years lack any clear regional pattern - with a mixture of unexceptional wide and narrow rings and clustering either absent or localised and patchy (e.g. Fig. 7d).

a)

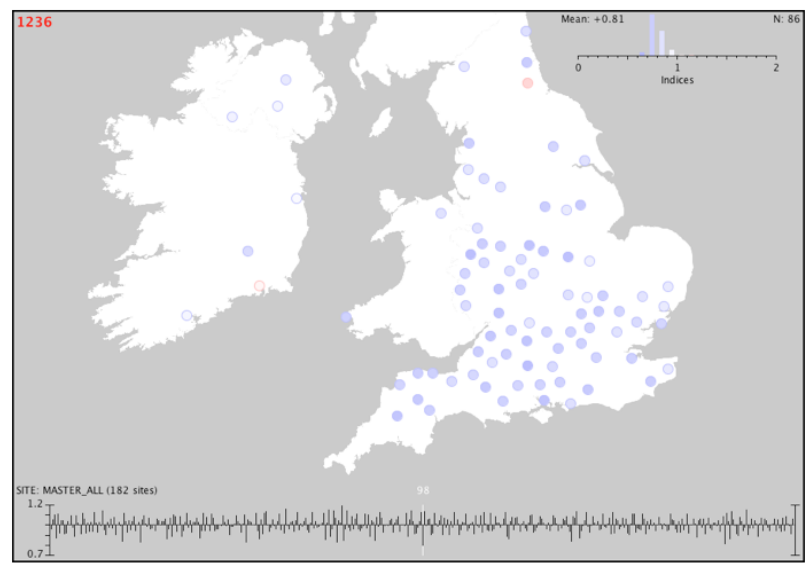

c)

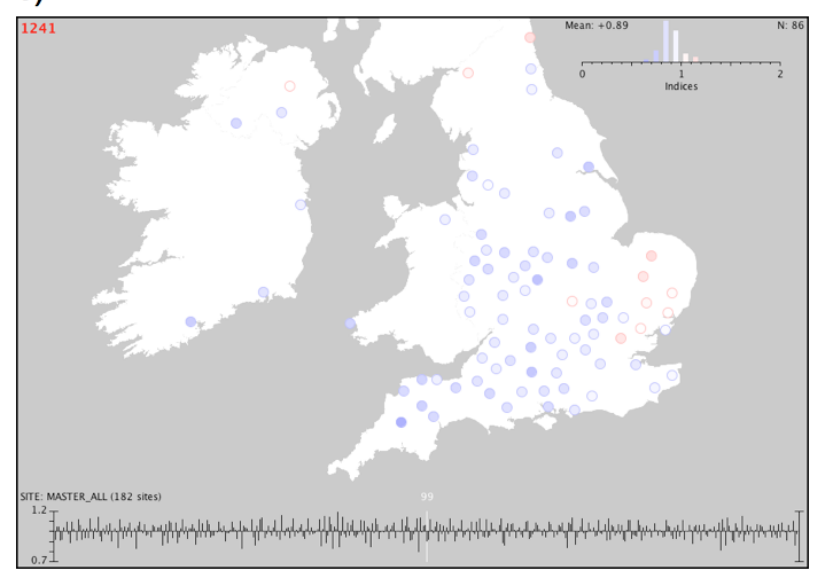

b)

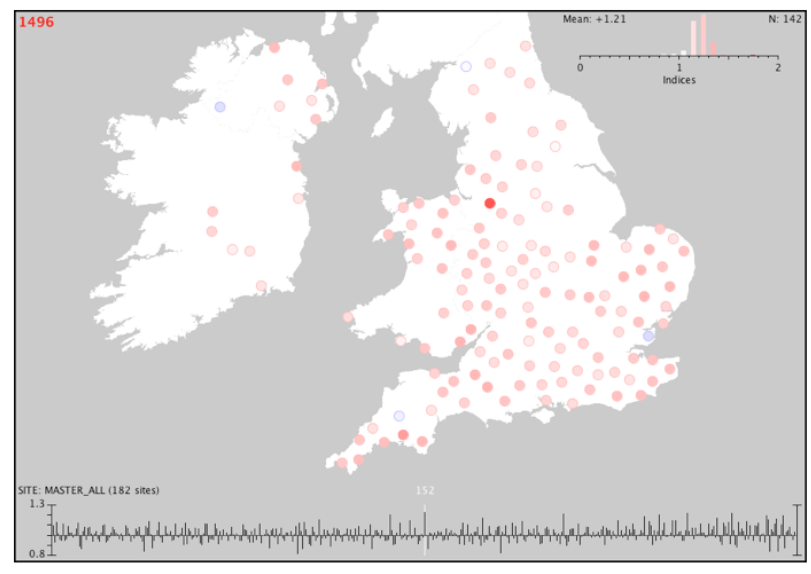

d)

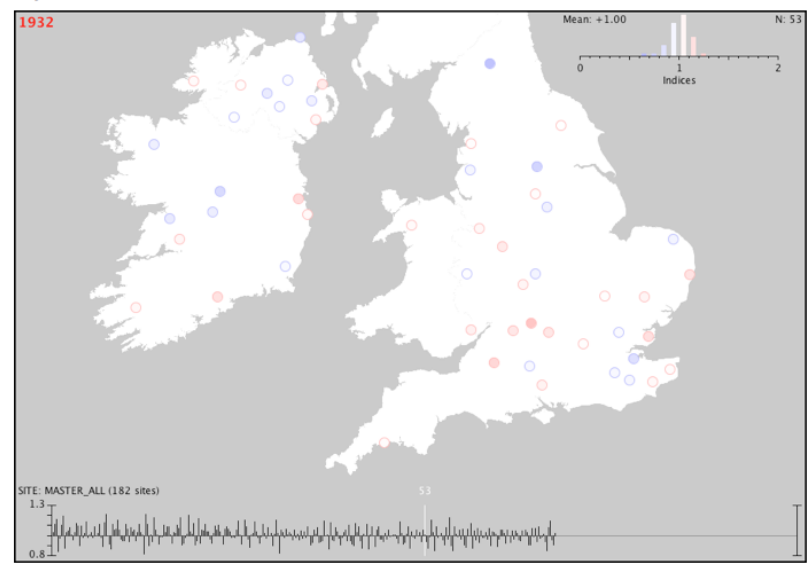

Fig. 7. Selected spatial patterns in the British Isles oak database (20 km merging applied). Blue and red dots show relatively narrow and wide rings, with colour intensity increasing with difference from 1.0 (the histogram shows the colour key). The master chronology is the robust mean of 181 merged site chronologies. 
Animation of yearly plots in Oak Mapper indicates temporal volatility in the frequency of pointer years. To approximate this, we defined pointer years in terms of an all-site master chronology as the $1 \%$ (roughly panBritish Isles) and 10\% (partial) lowest and highest indices, then counted these for overlapping 51-year blocks, every 25 years. To reduce bias associated with the high site sample depth of central-southern England, $20 \mathrm{~km}$ merging was applied and the master built from these merged sites. Frequency counts show considerable multi-decadal to centennial-scale variability (Fig. 8) with, as expected, low (high) counts corresponding to periods of low (high) inter-site correlations in Table 1. These results are insensitive to the flexibility of the standardisation spline.

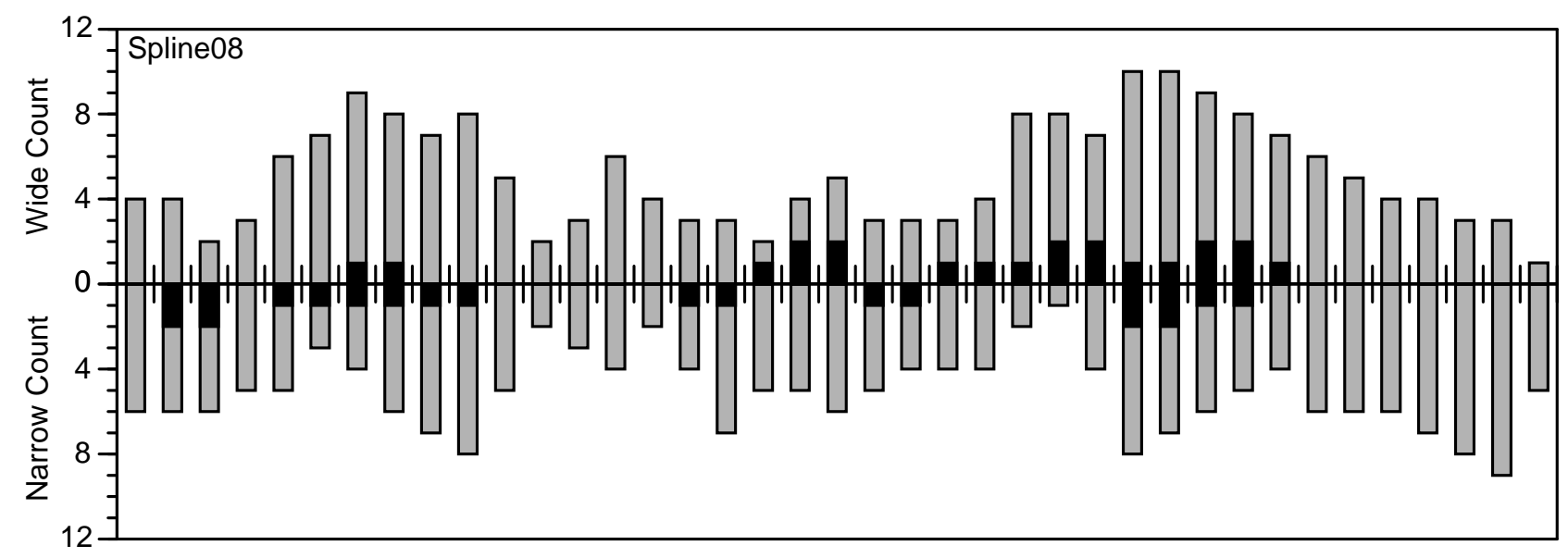

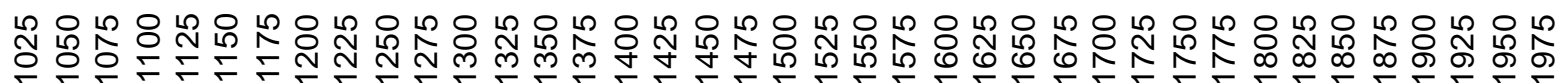

\section{Middle Year (CE) of 51-year Window}

Fig. 8. Frequency counts of locally wide and narrow rings for overlapping 51-year blocks, centred on the year shown $(1025,1050 \ldots$ 1975). Grey bars are counts of the $10 \%$ of years with indices less than 0.917 and the $10 \%$ of years with indices greater than 1.111 . Solid black is the subset of counts for the lowest $1 \%$ of indices $(<0.840)$ and the highest $1 \%(>1.194)$.

\section{Provenancing}

In western Europe dendroprovenancing using oak (Quercus spp.) and pine (Pinus spp.) has been successful in indicating the source growth areas of timbers used in shipwrecks, art-historical materials and in buildings where timber may have been transported long distances by river (e.g. Daly 2007, Haneca et al 2009, Bridge 2012). The current methods of comparing ring-width chronologies are acknowledged as being rather crude, but capable of distinguishing between growth areas hundreds of kilometres apart. The oak database provides an opportunity to investigate provenancing potential in an alternative way by exploiting the fact that we have numerous living tree chronologies over the last few centuries where we know the site location and can test our ability to identify it, based on correlations with the rest of the network. This is analogous to the situation where an artefact of unknown provenance is successfully crossdated then tested for provenance against the available network at that time (e.g. Bridge 2011). However, note that this is also a best-case 
scenario because the chronology being tested and the chronologies it will be tested against are likely to be amongst the highest quality in statistical terms.

To ensure that we are dealing with living trees, and therefore a known location, we use a 51-year window centred on 1950 (i.e. 1925-1975), which gives us 65 chronologies (Fig. 9). Fig. 9a is an example of a successful provenancing test, with high correlations against several (but not all) neighbouring sites and the highest correlation is with a close neighbour. Fig. $9 \mathrm{~b}$ is an example of a potential false positive - local correlations are relatively low and the most convincing (wrong) association is to a site over $200 \mathrm{~km}$ away. Fig. 9c shows an alternative provenancing fail situation where correlations are reasonable over too wide a geographic range to be useful. Fig. $9 \mathrm{~d}$ shows something similar although, in this case, it is possible that failure may relate primarily to the lack of nearby sites in the southwest.

a)

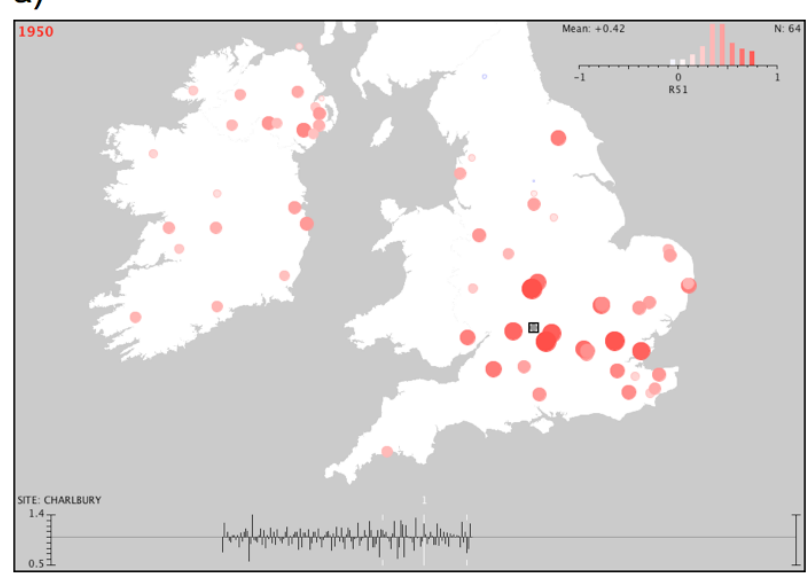

c)

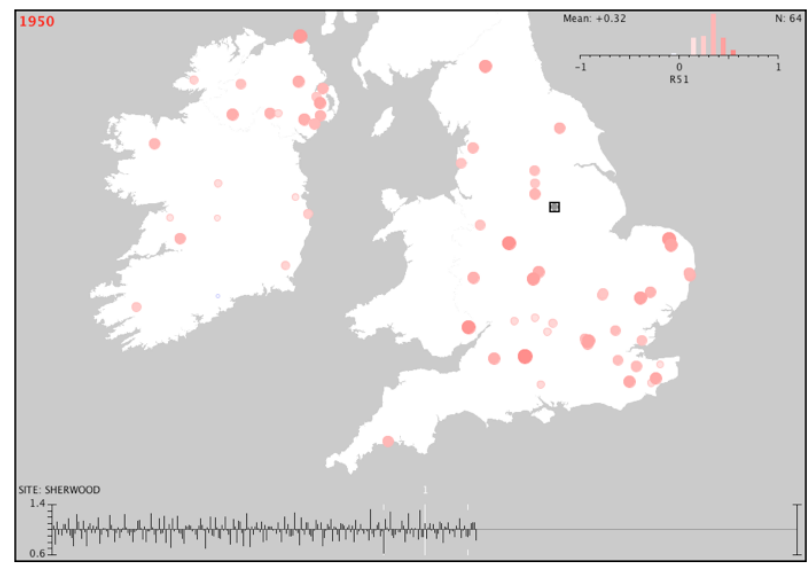

b)

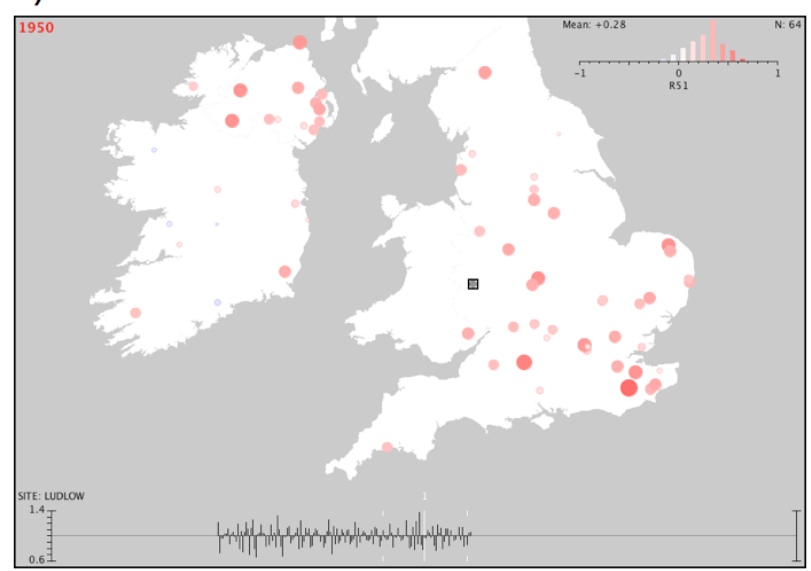

d)

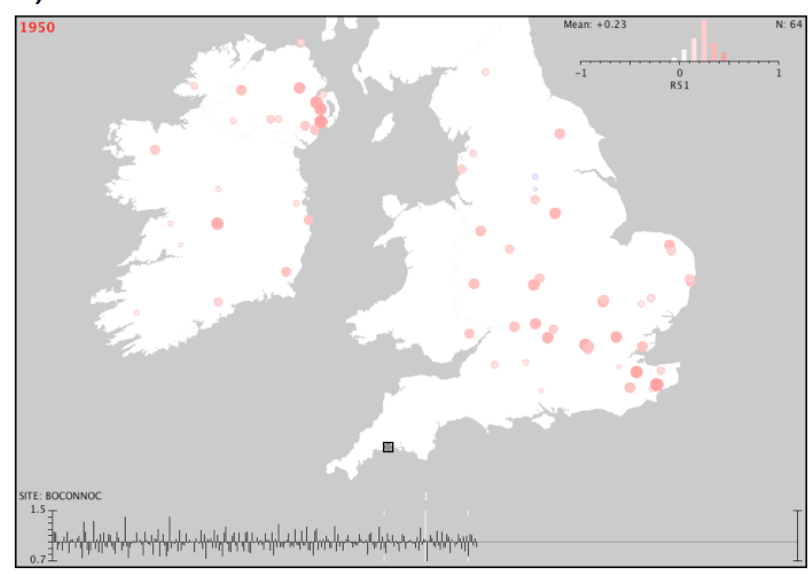

Fig. 9. Selected provenancing examples. Panels map correlations of the selected site (square) against the 64 other sites with complete data for the 51-year window centred on 1950. Colour intensity indicates the correlations (see histogram for key). Circle areas (proportional to Student's t) indicate statistical significance.

\section{Past climate}

The utility of massively-replicated European spatial networks of oak archaeological data for climate applications has recently been demonstrated. For example, Büntgen et al. (2011) produced a multi-millennial reconstruction of April through June precipitation for central Germany from several thousand oak samples, 
and Kelly et al. (2002) investigated pan-European oak pointer years, which they related to drought and atmospheric circulation indices. A recent pair of papers focussed on oak samples from English sub-regions (Cooper et al., 2013; Wilson et al., 2013) have produced millennial-scale reconstructions of March through July precipitation, with some weak evidence of regional differences. Moreover, the potential for millennialscale reconstruction of UK summer temperature and precipitation from stable isotopes in oak tree rings has also been clearly demonstrated (Young et al., 2015, and references therein).

The oak database compiled here extends to regions not included in the south-central England focus of Wilson et al. (2013), so an obvious research route would be to extend their analytical methods to a larger spatial domain (especially Ireland). However, two of the results presented in previous sections have relevance to climatology that are likely to be well worth exploring. Firstly, although regional patterns are generally quite subtle, some of them repeat multiple times (e.g. the east-west gradient evident in Fig. 6 and Fig. 7c) and may well relate to characteristic atmospheric circulation patterns. Secondly, the evolving frequency of pointer years (Fig. 8) may be indicative of evolving variability of selected climate conditions during the growing season.

\section{Discussion \& Conclusions}

The research presented here was initiated to explore the potential of British Isles archaeological oak tree-ring data for a range of applications - ranging from systematic review of current dating methodology through to millennial-scale climate reconstruction. A key element of our research methodology for each of the six applications we address is exploration of potential through data visualisation, primarily through mapping. In that context, the integrity of the oak database (including metadata) is central to our work and required a significant investment of time in quality control in order to minimise data errors. Intimate knowledge both of current practice and of the available data (MCB) exposed several issues with the data in its raw form. For example, one series in the International Tree Ring Databank (ITRDB) had metadata locating it to central southern England when in fact it is located in East Anglia (now corrected in the ITRDB). Another site appeared to be located in the sea, an error in the latitude record being at fault.

There is no doubt that the ideal data for our work would have been individual ring-width measurements. That would have allowed us to apply consistent standardisation and chronology construction methods and to truncate chronologies where sample depth is low. The current state of affairs largely precludes this because much of the data is only available at the level of site chronologies - requiring us to choose between running more detailed and consistent analyses on a much reduced dataset or to maximise spatial coverage by going with site chronologies. We decided to go with the latter for three reasons. First, maximising spatial coverage is critical for any regional-scale analysis and, as noted above, regional-scale mapping is the central element of our methodology. Second, because site-based analysis is in fact closest to current dating practice, it makes sense to at least begin at that point. Third, compiling a British Isles ring-width data base would require a vast amount of quality-control work on data that, in many cases, are not in the public domain.

Mapping archaeological data at the level of individual sites (Fig. 2) implicitly presumes that the location of a dated building is a useful approximation of the location the trees contributing the wood (i.e. that timber was locally sourced). This is a reasonable assumption in the case of relatively humble dwelling houses, although 
may not be appropriate in the case of grander cathedrals, monasteries and castles (Bridge 2012). Discarding sites, such as London, where imported timber is a known issue, removes some potential systematic problems, but clearly the residual chronologies will contain exceptions. Moreover, even for those sites that are locally sourced, proximity may well vary in both space and time. Spatial merging of sites and building chronologies using a robust mean proved to be an effective solution to this issue - evidenced by stronger spatial coherence amongst merged sites. This is because the increased sample depth of merged sites works to enhance the common signal and because the robust mean is specifically targeted at reducing (removing in extreme cases) the influence of outliers (Mosteller and Tukey, 1977). Outliers are more likely to be non-local sites, but mitigation will also operate in the case of local sites which are anomalous for other reasons (ecological, management, disturbance, etc). Useful visualisation side-effects of merging are removal of the messy overlaying of sites (compare Fig. 2 with Fig. 7) and reduced dominance of high sample depth regions.

An interesting result emerging from the crossdating methodology proof-of-concept work is that the typical high pass filtering of oak data, introduced by Baillie and co-workers in the 1960s, is near-optimal (Table 1). This warrants further attention, together with consideration of different series lengths and associated statistical significance. It would be appropriate to consider alternative standardisation approaches designed to maximise correlations, and therefore statistical significance, and to review (in that context) minimum series lengths that can be meaningfully crossdated. Intriguingly, Table 1 and Fig. 8 suggest likely centennial-scale variability. For example, sorting out multiple building phases of an $18^{\text {th }}$ century structure may be possible with rather shorter series lengths than a comparable $13^{\text {th }}$ century structure, because the signal is likely to be much stronger in the former case.

We showed one example of how a database error (Blackwater mean metadata error) can be easily identified through visualisation of correlations between sites and an all-site master chronology. Visualisation also helped to identify several obvious location errors (e.g. sites plotting in the sea). Other errors are less obvious and there are certain to be better objective approaches for systematic error checking than visualisation. However, as previously noted in the context of visualisation, only potential errors can be identified and it is best to go back to the original researcher or material to confirm crossdating and/or site location. This is because imported timber will almost always be a possibility for archaeological sites and because weak series matches may be a consequence of factors such as forest management or disease.

An unequivocal result emerging from the preliminary analyses presented here is the crossdating benefit of working with merged sites. This is most strikingly apparent in Table 1 where correlations with an all-site master chronology are always much higher than comparable inter-site correlations, due to the amplification of the pan-British Isles climate signal in the often massively-replicated master chronology. There is also enough evidence of the merits of regional chronologies to warrant closer investigation. For example, sites in Ireland usually have higher correlations against an all-Ireland master than the pan-British Isles master (e.g. Fig. 6). However, the non-stationary of regional relationships and the generally negative provenancing results (Fig. 9) suggest that regional chronologies may be of variable utility, both in time and space. In the context of climate reconstruction, it is possible that this non-stationarity may confound reconstruction efforts, although it is also possible that it is in some way indicative of the evolving character of climate drivers that are themselves forcing the waxing and waning of regional-scale differences. 
Clear evidence of both pan-British Isles (Fig. 7a,b) and sub-regional (Fig. 7c) pointer years looks promising in terms of providing dendrochronologists with a useful alternative to sole reliance on correlation analysis. For example, one might reasonably be suspicious of a statistically significant match over the decades surrounding $1496 \mathrm{CE}$ if that year does not register as a wide ring (Fig. 7b). On the other hand, regional exceptions (e.g. Fig. 7c) point to the likely usefulness of regional pointer year analysis, although which regions and the appropriate spatial scale of such analysis are clearly non-trivial questions.

It also seems likely that the evolving frequency of pointer years through the last millennium (Fig. 8) carries useful information about decadal-scale variability of British Isles climate. The $14^{\text {th }}$ and $18^{\text {th }}$ centuries look to be particularly interesting in this context with relatively few/many extremes respectively. Inferring $14^{\text {th }}$ century climate conditions based on $20^{\text {th }}$ century relationships between pointer years and the instrumental climate record looks feasible, but interpreting the $18^{\text {th }}$ century is likely to be confounded by what appears to be a noanalogue situation - the instrumental period having a paucity of the extremes characterising the $18^{\text {th }}$ century, especially positive pointer years.

The provenancing results are somewhat discouraging, but not without hope. It is apparent from Fig. 9 that provenancing can work in some cases, but the preliminary results presented here suggest that is more likely to fail than to succeed. A high density of sites is a prerequisite, if for no other reason than that the best match in a relatively sparse network may well have been bettered elsewhere if spatial coverage were more complete. Note though that this fairly negative conclusion relates to a provenancing scale of the order of about $100 \mathrm{~km}$ and that regional chronology potential, outlined above, suggests that provenancing may have potential at a coarser spatial scale. For example, it may often be possible to confidently distinguish between generic Ireland and England source areas. This line of reasoning naturally points to the use of regional chronologies, with the associated sample depth advantages.

\section{Conclusions}

The research presented here set about building the oak database, developing a software tool to explore it, and demonstrating the potential for mining the data base for multiple applications. The first of these has successfully been completed, although we note that there remains much that could be done to improve the database quality and that it is constantly growing as more material becomes available. Because many of the site chronologies are the intellectual property of commercial consultants (see acknowledgements), the database is not currently in the public domain.

The software tool (Oak Mapper) is complete, although additional analytical components will be incrementally added as the data mining applications are pursued. The focus in this paper has been on Oak Mapper's basic visualisation functionality, although key elements of that cannot be effectively shown here, such as interactive adjustment of various parameters, with near-instantaneous display update. For example, scrolling of Fig. 6 through each year of the last millennium reveals dramatic evolution of the correlation spatial pattern. Modification of Oak Mapper to deal with other spatial domains and data sets is feasible, but would require some additional coding work to deal with the former.

Results are mixed for the six applications where we have parsimoniously investigated the potential of mining the oak database, but fruitful directions for future research have been identified in each case. These will be 
picked up by us in subsequent substantive investigations of each. However, we are also hopeful that the scoping exercise presented here will encourage similar work by other researchers. Particularly exciting is the potential for dramatically extending the spatial domain through a collaborative pan-European investigation.

\section{References}

Babbage, C. 1837. The Ninth Bridgewater Treatise (Note M). Cambridge University Press, Cambridge.

Baillie, M.G.L. 1982. Tree Rings and Archaeology. University of Chicago Press, Chicago.

Baillie, M.G.L., Pilcher, J.R. 1973. A simple crossdating program for tree-ring research. Tree-Ring Bulletin, 33, 7-14.

Baillie, M.G.L., Hillam, J., Briffa, K.R. and Brown, D.M. 1985. Re-dating the English art-historical tree-ring chronologies. Nature, 315, 317-319.

Berger, R., Giertz, V., Horn, W. 1971. Can German tree-ring curves be applied to England and France? Vernacular Architecture, 2, 3-6.

Bridge, M.C. 2011. Resource exploitation and wood mobility in northern European oak: dendroprovenancing of individual timbers from the Mary Rose (1510/11-1545). International Journal of Nautical Archaeology, 40, 417-423.

Bridge, M.C. 2012. Locating the origins of wood resources: a review of dendroprovenancing. Journal of Archaeological Science, 39, 2828-2834.

Büntgen, U., Tegel, W., Nicolussi, K., McCormick, M., Frank, D., Trouet, V., Kaplan, J.O., Herzig, F., Heussner, K.-U., Wanner, H., Luterbacher, J., Esper, J. 2011. 2500 years of European climate variability and human susceptibility. Science, 331, 578-582.

Cooper, R.J., Melvin, T.M., Tyers, I, Wilson, R.J.S., Briffa, K.R. 2013. A tree-ring reconstruction of East Anglian (UK) hydroclimate variability over the last millennium. Climate Dynamics, 40, 1019-1039.

Daly, A., 2007. Timber, Trade and Tree-Rings. A dendrochronological analysis of structural oak timber in North Europe, CAD 1000 to CAD 1650, unpublished PhD thesis, University of Southern Denmark.

Haneca, K., Cufar, K., Beeckman, H., 2009. Oaks, tree-rings and wooden cultural heritage: a review of the main characteristics and applications of oak dendrochronology in Europe. Journal of Archaeological Science, 36, $1 \mathrm{e} 11$.

Kelly, P.M., Leuschner, H.H., Briffa, K.R., Harris, I.C. 2002. The climatic interpretation of pan-European signature years in oak ring-width series. The Holocene, 12, 689-694.

Litton, C.D., Zainodin, H.J. 1991 Statistical models of dendrochronology, Journal of Archaeological Science,18, 29-40.

Lowther, A.W.G. 1951. Date of timbers from the spire of Chilcomb Church and from the wreck in the river Hamble: some evidence from dendrochronology. Proceedings of the Hampshire Field Club, 17, 130133.

Miles, D.W.H., Bridge, M.C. 2008. Westminster Abbey, London: Tree-Ring Dating of the Chests and Fittings, English Heritage Research Department Report Series, 3-2008. 
Mosteller, F., Tukey J.W. 1977. Data Analysis and Regression: a Second Course in Statistics, AddisonWesley, Reading, Massachusetts.

Schove, D.J., Lowther, A.W.G. 1957. Tree-rings and Medieval Archaeology. Medieval Archaeology, 1, 7895.

Young, G.H.F., Loader, N.J., McCarroll, D., Bale, R.J., Demmler, J.C., Miles, D., Nayling, N.T., Rinne, K.T., Robertson, I., Watts, C., Whitney, M. 2015. Oxygen stable isotope ratios from British oak tree- rings provide a strong and consistent record of past changes in summer rainfall. Climate Dynamics. Published online 25 March. DOI: 10.1007/s00382-015-2559-4.

Wilson, R., Miles, D., Loader, N.J., Melvin, T., Cunningham, L., Cooper, R., Briffa, K. 2013. A millennial long March-July precipitation reconstruction for southern-central England. Climate Dynamics, 40, 9971017.

\section{Acknowledgements}

We gratefully acknowledge the following individuals and organisations who contributed oak archaeological data. Data were sourced from individual sites worked on by MCB and his colleagues in the Oxford Dendrochronology Laboratory and its predecessors, English Heritage funded sites (where the information is in the public domain in the reports that they produce) and other site chronologies kindly supplied by lan Tyers, the Nottingham Tree Ring Laboratory (mostly through Robert Howard) and the former Sheffield Dendrochronology Laboratory (mostly through Cathy Tyers), along with Irish material supplied by David Brown (Queen's University Belfast), and other sites from Anne Crone, Coralie Mills, and Rob Wilson. In addition site information was obtained from the International Tree Ring Databank, contributed by Jennifer Hillam, Tom Melvin and Keith Briffa. 